\title{
Field applications of cyclodextrin-aided sludge dewatering
}

\author{
S. Banerjee ${ }^{1} \&$ S. Wright ${ }^{2}$ \\ ${ }^{I}$ Institute of Paper Science \& Technology, \\ School of Chemical \& Biomolecular Engineering, \\ Georgia Institute of Technology, USA \\ ${ }^{2}$ Axchem Inc., USA
}

\begin{abstract}
Cyclodextrins (CDs) increase the cake solids and the drainage rate of belt- or screw-pressed biological or primary sludge when added to the sludge slurry along with conventional sludge conditioning chemicals. These benefits are obtained at very low $\mathrm{CD}$ dosage. For example, a 2.8 percentage point increase in cake solids was obtained in a full-scale trial with mixed primary and biological sludge at a paper mill wastewater system. CDs also decrease the specific resistance to filtration and increase the capture rate of solids during belt pressing. They are able to aggregate charged polymers, and, by inference, sludge particles treated with the polymers. Results from full-scale trials at two paper mills and a municipal wastewater treatment system are discussed. In all cases, some combination of higher cake solids, better drainage, better filtrate clarity and lower polymer dosage was obtained. The $\mathrm{CD}$ application for sludge dewatering is being introduced commercially.
\end{abstract}

Keywords: sludge, dewatering, cyclodextrin, polymer, cake solids.

\section{Introduction}

Cyclodextrins (CDs) are torus-like rings assembled from six, seven, or eight glucopyranose units: $\alpha-, \beta-$, and $\gamma-\mathrm{CD}$, respectively. The structure of $\beta-\mathrm{CD}$ is illustrated in figure 1 . CDs have a cylindrical structure with a hydrophobic cavity and a hydrophilic exterior. They are non-toxic commodity chemicals, and are prepared by the action of bacteria on starch [1]. Practical applications include solubility enhancement of hydrophobic solutes such as pharmaceuticals [2], the 
stabilization of volatile compounds for odour control $[3,4]$ the controlled release of pesticides [5] and the detackification of adhesive contaminants in recycle paper mills [6].

We have recently shown $[7,8]$ that CDs improve the dewatering of both fibrous and biological sludge through some combination of higher cake solids, faster dewatering and lower polymer use. They also increase the capture rate of solids during belt pressing. The CDs are added to the sludge slurry along with conventional conditioning chemicals. An illustration of floc densification is provided in figure 2. Laboratory work has shown that CDs increase the surface tension of c-PAM polymers in water and reduce the turbidity, indicating that they are able to aggregate the charged polymers, and, by inference, sludge particles treated with the polymer [7]. CDs are believed to reduce excessively charged regions of the polymer-treated surface of the sludge, thereby facilitating its flocculation.

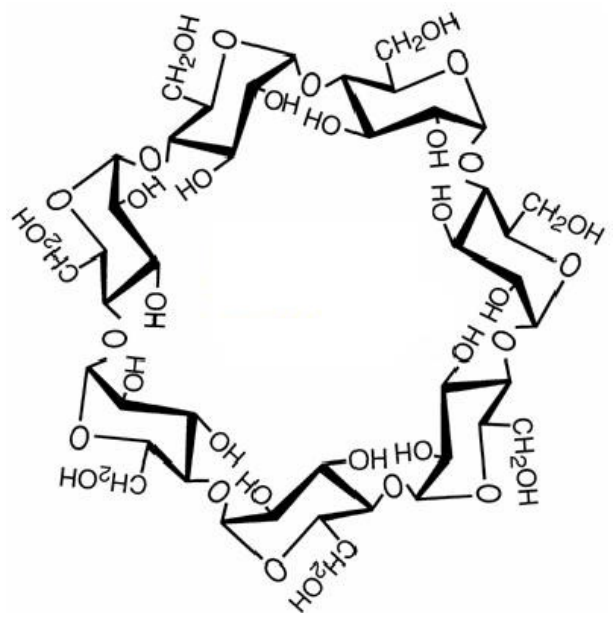

Figure 1: $\quad$ Structure of $\beta$-cyclodextrin.

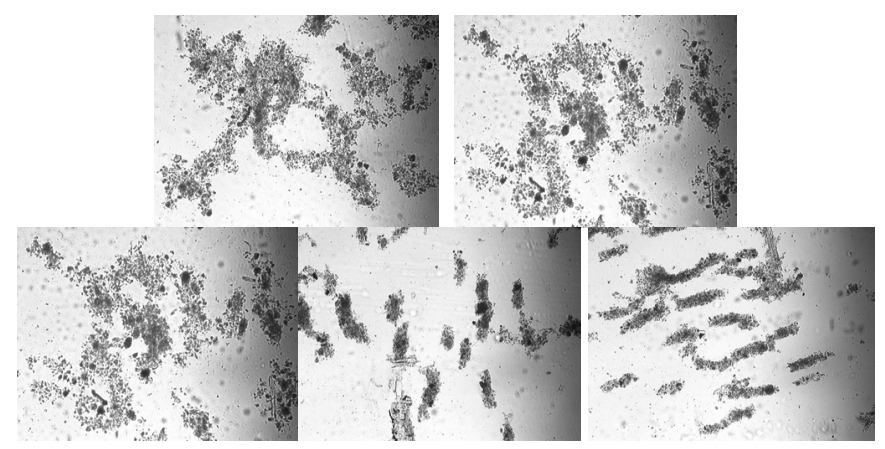

Figure 2: $\quad$ Micrographs of biosludge with $0.5 \mathrm{~kg} /$ tonne c-PAM and increasing dosages of $\beta-\mathrm{CD}$ (from left to right: $0,0.00$. 
A striking feature of the application is that the benefits are obtained at very low CD dosage of about 0.05-0.4 kg/tonne of dry solids. Cyclodextrins are relatively inexpensive commodity chemicals and the very low dosage required makes the application commercially attractive. Several CDs have been evaluated to date, and they have all provided roughly similar results. As $\beta-\mathrm{CD}$ is presently the cheapest of the series tested [7], it was used in our full-scale trials. In this paper we demonstrate and discuss three full-scale applications of $\beta$-CD in sludge dewatering.

\section{Mill trial at Wisconsin Rapids}

A full-scale trial was run under normal mill operating conditions at the Stora Enso wastewater centre at Wisconsin Rapids, WI. The centre collects effluent from three paper mills. The effluent is routed through a primary clarifier and the overflow treated in an activated sludge treatment system. The primary and secondary sludge are mixed in a $6.8 \mathrm{~m}^{3}$ gallon blend tank from which the sludge is pumped at 3,000 litres per minute to four belt presses. Flow from the primary and secondary thickeners is 1,000 and 1,900 litres per minute, respectively. Ferric chloride (38\% active) was added to the blend tank at $600 \mathrm{ml} / \mathrm{min}$. A coagulant, Stockhausen $187 \mathrm{KH}$ at $6.8 \mathrm{~kg} /$ tonne, and a flocculant, Stockhausen $\mathrm{K} 133 \mathrm{~L}$ at $73.4 \mathrm{~kg} /$ tonne, were added to each individual press. A $\beta$-CD solution was pumped into the sludge slurry along with the polymer. An Andritz belt press was used in this study.

The CD was added with the polymer at 0.05 and $0.09 \mathrm{~kg} /$ tonne, but the results from both applications were similar and the results are interpreted on an on/off basis for the CD. Figure 3 summarizes the results with the CDs. The average pressed solids rose from a baseline value of $30.8 \%$ to $33.6 \%$, an increase of 2.8 percentage points. The mill reports a historical baseline of $28 \%$ solids. A t-test

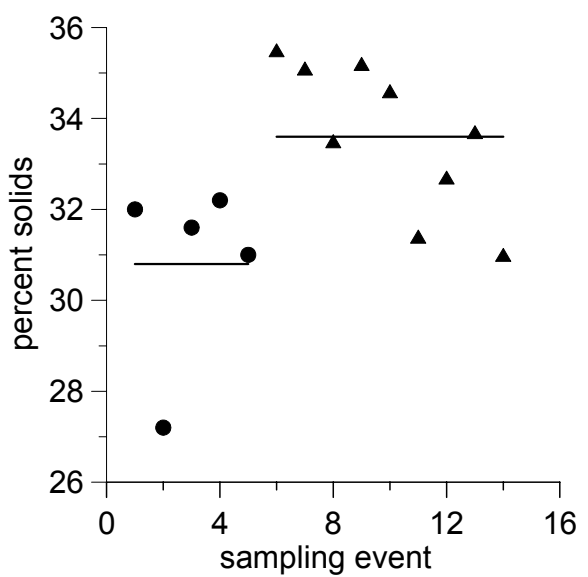

Figure 3: $\quad$ Cake solids with (triangles) and without (circles) $\beta$-CD for press 1 . The lines are averages for each case. 
shows the means to be different at a $99 \%$ confidence level. Visually, the $\beta$-CDs caused a clear difference in the structure of the sludge. Much better flocs were obtained, and the dry line moved back on the belt indicating better drainage.

\section{Trial at a paper mill in the Southeastern US}

The scatter in figure 3 arises from variability in the incoming sludge and a twoday trial was run at another mill to more clearly demonstrate the effect of the CD. The sludge was a 1:1 mixture of primary and biological solids. It was dosed with 4-8 kg/ton Axchem AF 9510 polymer and $0.1 \mathrm{~kg} /$ ton of $\beta-C D$. Ferric dosage was determined by a $\mathrm{pH}$ set point of 6.8 .

Filtrate TSS values are plotted in figure 4; the abscissa are sampling times. In all but one case, the presence of the CD reduced the TSS drastically. This reduction was usually immediate; the filtrate clarity and the floc structure improved within ten minutes of $\mathrm{CD}$ addition. The only exception was the last TSS value in the plot, which was high even though the CD was on. However, the headbox level increased at that time, which could have signalled a change in the nature of the feed sludge.

In several instances the addition of CD increased the viscosity of the filtrate, indicating polymer overdose. This is clear evidence that the $\mathrm{CD}$ reduced polymer demand, which was the main objective of the trial. The mill has been using the $\beta$ $\mathrm{CD}$ continuously for the past two months and has realized average polymer saving of $29 \%$.

Laboratory scale sludge gravity drainage measurements were also made onsite by Axchem. A nominal dose of $0.2 \mathrm{~kg} /$ tonne of CD increased gravity drainage by 18.8 percent. Higher CD dosages of $0.35 \mathrm{~kg} /$ tonne and greater were less effective. Results from a typical drainage measurement are illustrated in figure 5 . Here, $100 \mathrm{ml}$ of the slurry was filtered through a screen and the weight of the filtrate was monitored continuously and converted to volume. The CD clearly increases both the drainage and the degree of drainage.

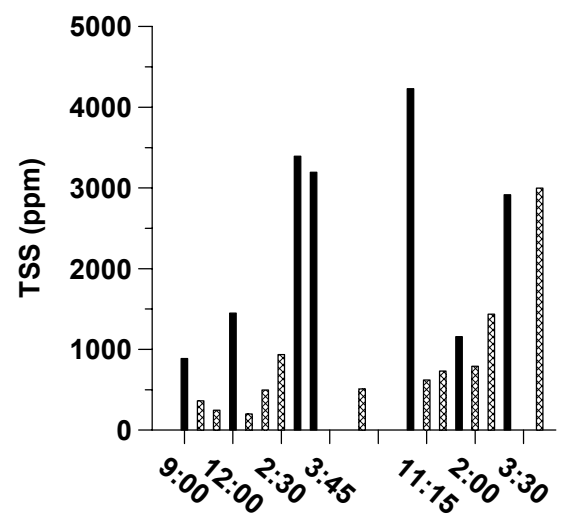

Figure 4: $\quad$ CD off (bold), CD on (hatched). 


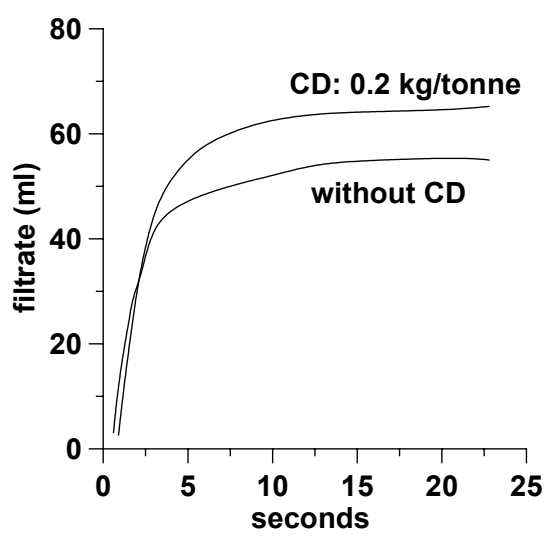

Figure 5: $\quad$ Effect of $\beta-C D$ on drainage rate.

\section{Trial at a municipal water treatment facility}

A trial was run at a municipal wastewater treatment plant in the Savannah, GA area. The plant dewaters aerobically digested sludge on a large Ashbrook belt filter press. The $\beta-\mathrm{CD}$ was made down to a $1 \%$ solution and metered into the sludge line before polymer addition.

The belt filter press was first optimized using EM 540BD polymer at a dose of $4 \mathrm{~kg} /$ tonne. A baseline cake solids of $12.8 \%$ was obtained. When the $\beta-C D$ solution was metered in at $0.2 \mathrm{~kg} /$ tonne, the cake solids increased by nearly one percentage point to $13.71 \%$. The polymer dose was then lowered to $3 \mathrm{~kg} /$ tonne, whereupon the cake solids fell to $13.4 \%$. The $\beta$-CD dose was then decreased to $0.1 \mathrm{~kg} /$ tonne; the cake solids fell to $13.1 \%$. At this point CD addition was discontinued while the polymer dose was left low. The cake dropped to $12.3 \%$ which was just slightly lower than the first sample which had no CD. The difference, $12.8 \%$ vs. $12.3 \%$ is a consequence of the lower polymer dose: 4 $\mathrm{kg} /$ tonne vs $3 \mathrm{~kg} /$ tonne. Finally, the CD addition was resumed at $0.17 \mathrm{~kg} /$ tonne, at the low polymer level; the cake solids jumped back up to $12.9 \%$.

These results show that the $\beta-\mathrm{CD}$ increased cake solids by $0.5-1 \%$. One very noticeable, but un-quantified affect, was the effect on free drainage. The addition of the CD dramatically improved drainage as seen by the clean belt fabric in the conditioned sludge head-box. This was not the case without the CD. We estimated that the addition $\mathrm{CD}$ could increase sludge production rates by as much as $25 \%$.

\section{Conclusions}

We have shown that CDs in general, and $\beta-C D$ in particular, contribute to sludge dewatering through a combination of improved cake solids, lower polymer dose better drainage, and improved filtrate clarity. Different facilities emphasize different benefits. For example, if the sludge is incinerated, then high cake solids 
are critical. If the sludge is landfilled, then the cost reduction taken through a lower polymer dose is more important. Filtrate clarity is always important, since the solids that leave with the filtrate will need to be reprocessed. Also, highsolids filtrates lead to screen plugging. Drainage is important in facilities that are limited by the number of presses available.

While we have not discussed results from all the sludges processed, the CD makes the greatest contribution to sludges that can only be presently pressed to relatively low solids. For example, sludge from recycle paper mills can be routinely pressed to up to $60 \%$ solids without $\mathrm{CDs}$ and the benefit of the $\mathrm{CD}$ is small. Also, these sludges use low polymer dose to begin with, so the potential for cost-savings is also low.

Much remains to be done on the fundamental aspects of the process. We know that the CD aggregates the polymer, and by extension, the particles agglomerated be the polymer. The mechanism has yet to be confirmed. The very low dose that is optimum suggests a "hot-spot" mechanism, i.e. the CDs act on small regions of the agglomerate that inhibit consolidation. Overdosing polymer causes particle repulsion because the charged regions repel one another. Even if the sludge is optimally dosed on average, there must be regions that are either overdosed or underdosed. The overdosed regions represent hot spots and it is attractive to attribute the performance of the CDs to the neutralization of these charged hot spots. The ability of CDs to neutralize charge is known [9]). Certainly, this would explain why the CD provides benefit at such low doses.

The cost of $\beta-C D$ is three to five times higher than that of a typical sludge conditioning polymer, but it is applied at very low doses so the increase in overall chemical cost is relatively small. This cost is more than offset by the savings realized from the reduced polymer dosage. The benefits of the CD are incremental; the $\mathrm{CD}$ essentially boosts the performance of the polymer(s) applied with regard to cake solids, drying rate, and capture efficiency. The cost:benefits are site-specific, but they are especially attractive at locations where sludge disposal costs are high.

The Southeastern mill discussed above has been using the CD for two months and has reduced its polymer costs by $29 \%$. Several trials at other facilities in the US have been run successfully and we anticipate additional implementations. Finally, we note that CDs are biologically derived products. Sludge conditioning polymers are derived from hydrocarbons, so that the displacement of polymers by $\mathrm{CD}$ carries both economic and socio-political benefit.

\section{References}

[1] Tonkova, A., Bacterial cyclodextrin glucanotransferase. Enzyme Microb. Technol., 22, pp. 678-686, 1998.

[2] Charumanee, S., Titwan, A., Sirithunyalug, J. Weiss-Greiler, P., Wolschann, P., Viemstein, H. \& Okonogi, S., Thermodynamics of the encapsulation by cyclodextrins. J. Chemical Tech. Biotech., 81, pp. 523$529,2006$. 
[3] Lo Nostro, P., Fratoni, L., Ridi, F. \& Baglioni, P., Surface treatment on Tercel fabric: grafting with $\beta$-cyclodextrin. J. Appl. Polymer Sci., 88, pp. 706-715, 2003.

[4] Goubet, I., Le Quere, J-L., Semon, E., Seuvre, A.-M. \& Voilley, A., Competition between aromatic compounds for the binding on $\beta$ cyclodextrins: Study of the nature of interactions. ACS Symposium Series, Oxford University Press, 763, pp. 246-259, 2000.

[5] Szente, L. (1998) Stable, controlled-release organophosphorous pesticides entrapped in $\beta$-cyclodextrin. I. Solid state characteristics. J. Thermal Analysis and Calorimetry, 51, pp. 957-963, 1998.

[6] Banerjee, S., Method for altering the tack of materials, patents pending.

[7] Hartong, B.H., Abu-Daabes, M., Le, T., Saidan, M. \& Banerjee, S., Sludge dewatering with cyclodextrins, Water Res., 41, pp. 1201-1206, 2007.

[8] Banerjee, S., Method for improving the consolidation and dewatering of suspended particulate matter, patents pending.

[9] Eddaoudi, M., Baszkin, A., Parrot-Lopez, H., Boissonnade, M.M. \& Coleman, A. W., Divalent Cation-Cyclodextrin Interactions at the Air-Water Interface. A Three-Stage Process. Langmuir, 11, pp. 13-15, 1995. 